sort of figure that surgical results must be balanced.

While late surgery in a younger person must take account of the risks of rebleeding in the very long term, ${ }^{3}$ this is obviously not so in the elderly, whose mean expectation of life is in any case limited. It is not valid to compare the treatment of an aneurysmal subarachnoid haemorrhage with that of a fractured hip, an intestinal obstruction, or a dissecting aneurysm in an old person. Patients with the latter conditions will die if left untreated. Most patients with a ruptured aneurysm who survive the first haemorrhage and the next few weeks will recover to resume a normal life without any surgical treatment.

R S MAURICE-WILLIAMS Regional Neurosurgical Unit, Brook General Hospital

1 Martindale, B V, and Garfield, J, British Medical fournal, 1978, 1, 465

27, 273 C, et al, Archives of Neurology, 1972 27, 273. 1978, 1, 1310 .

\section{Antibiotic resistance in Streptococcus} pneumoniae and Haemophilus influenzae

SIR,-May I be allowed to make an observation on the findings of the study group as published by Dr A J Howard and his colleagues (24 June, p 1657) after reporting my own experience in this health district?

To determine the changing pattern of antibiotic sensitivity in this locality a survey of all significant pathogens isolated in the first three months of 1977 and 1978 was undertaken. This was done by recording the results of routine disc tests and no attempt was made to find out the minimum inhibitory concentrations. The number of strains of the two organisms surveyed by the study group which were tested in these periods were as follows: Haemophilus influenzae 80 in 1977 and 116 in 1978; Streptococcus pneumoniae 33 in 1977 and 50 in 1978 (all in the first three months of each year). The percentages of resistant strains found are given in the table.

Percentage of antibiotic-resistant strains isolated in the first three months of 1977 and 1978

\begin{tabular}{l|c|c|c|c}
\hline \multirow{2}{*}{ Antibiotics } & \multicolumn{2}{|c|}{ H influenzae } & \multicolumn{2}{c}{ Str pneumoniae } \\
\cline { 2 - 4 } & 1977 & 1978 & 1977 & 1978 \\
\hline Ampicillin & 0 & $2 \cdot 5 *$ & 0 & 0 \\
Tetracycline & 0 & 0 & 9 & 6 \\
Co-trimoxazole & 0 & $4 \cdot 3$ & 0 & 0 \\
& & & &
\end{tabular}

*All were $\beta$-lactamase producers (total of three strains).

It can be seen from this table that the resistant figures found in this district in early 1977 were not similar to the national average of findings from 20 other laboratories as reported by the study group. Moreover, there were wide variations in the percentages of resistant strains found in the 20 different laboratories and only a very few matched with the national average. The percentages of tetracycline-resistant Str pneumoniae and ampicillin-resistant $H$ influenzae strains from Nottingham (as mentioned in the report) were 14.8 and $1 \cdot 1$ respectively. Our findings from this district laboratory in the same period were 9 and 0 respectively. This difference is of much interest as the distance between these two laboratories is only about 15 miles
$(24 \mathrm{~km})$. In the early part of 1978 the figures in our laboratory had changed to 6 and $2 \cdot 5$ respectively. Thus the conclusion which I would draw is that it is good to know the national average, but it is of limited practical value because of variations from district to district and year to year. The clinicians should be better guided by the local microbiologist.

M RAHMAN

\section{Department of Microbiology,}

Kutton-in-Ashfield, Notts

\section{Costs in perspective}

SIR,-Your leading article "Treatment with bile acids" (29 July, p 309) refers to pharmaceutical treatment with an "expensive new agent" costing about $£ 1$ a day. I wonder how many of your readers realise that an average day's stay in an acute hospital bed now costs more than 30 times as much? Will we ever see the relatively low price of medicines in perspective against the very high costs of hospital care?

George TeELING-SMith Office of Health Economics

London W1

\section{A numbers game: understanding normal standards}

SIR,-Your leading article (24 June, p 1651) is a useful reminder of some of the factors which should be considered in the assessment of results of laboratory or other tests. Frequently factors which may influence the results obtained for a particular sample, including techniques of collection and analysis and other factors that may influence the specimen before it can be obtained, are completely ignored.

Under clinical conditions a doctor may consider a result in the light of the patient's sex and possibly therapy, but rarely will the multitude of other factors, including time of day, biological rhythm, diet, or exercise, be considered. It is important to point out, particularly to medical students at a time when more emphasis seems to be placed on examination of results than examination of patients, that correct interpretation of "values of $x$ " should be based on both an appreciation of the significance of altered levels of " $x$ " and an understanding of the extraneous factors which may influence the results. Furthermore, it may not be adequate to compare the "level for $x$ " with an inappropriate reference range, which may take no account of either the variations of different measuring techniques or the individual's age, sex, or race. The significance of a result may be obscured by the fact that it lies inside the reference range and may be appreciated more fully when related back to the individual. Reference ranges may be constructed using "normal" people who are neither ill nor particularly healthy, and special consideration may be necessary when a fit individual (for example, an athlete) consults his doctor.

Our own work, a longitudinal study of intensively trained competitive swimmers, shows that the haematological characteristics of such individuals vary within only very narrow ranges compared with the wide normal ranges expressed in standard haematological reference books and used in clinical practice. Small changes of the values for an individual away from his normal range, which may adversely affect his performance, may not easily be recognised. If long-term monitoring is envisaged or required personal profiles need to be developed for particular individuals. Using such personal normal standards subtle changes may be detected and assessed more easily at an early stage.

\section{P L T WILLAN}

K M Bagnall

Department of Anatomy,

Medical School

University of Manchester

D W KELLETT

Didsbury Faculty of Education,

Manchester Polytechnic

\section{Swaddling and congenital dislocation of the hip}

SIR,-A recent article in the Sunday Times (16 July) described the use of swaddling and a swaddling board by a child psychologist in the treatment of hyperactive babies. From the orthopaedic standpoint, this is absolutely contraindicated ${ }^{12}$ owing to the detrimental effects of splinting the hip in flexion and adduction on the development of the young hip. ${ }^{3}$

The incidence of congenital dislocation of the hip has been well established ${ }^{4} 5$ and runs at approximately 1.5 to 1.7 per 1000 live births-that is, an incidence of between $0 \cdot 1$ and $0.2 \%$. As the article mentioned the Navajo Indians I feel one ought to quote the incidence of congenital dislocated hip in that population. It again has been well established ${ }^{6}$ and is in excess of $3 \%$. Other communities where swaddling is practised, such as northern Italy and Germany, have a similarly increased incidence of congenital dislocation of the hip.

I would therefore make a plea that swaddling be completely abandoned and rejected. I am sure your readers are only too well aware that the orthopaedic work load is quite heavy enough without any help from the child psychologist.

M A SMITH

Alfred I duPont Institute,

Wilmington, Delaware

Apley, A G, A System of Orthopaedics and Fractures. 5 th edn. London, Butterworth, 1977

Salter, R B Textbook of Disord Musculoskeletal System. Baltimore, Williams and

Wilkins, 1970.
${ }^{3}$ Salter, R B, in Modern Trends in Orthopaedics, No 5, ed W B Graham. New York, AppletonCentury-Crofts, 1967

- Barlow, T G, Fournal of Bone and foint Surgery, $1962,44 B, 292$.

'Rosen, S, fournal of Bone and foint Surgery, 1962, 44B, 284

Pemberton, P A, fournal of Bone and foint Surgery,

\section{Propranolol in black hypertensives}

SIR,-In 1968 Dr Gerald Humphreys and I published in the $B M \mathcal{F}$ a paper entitled "Ineffectiveness of propranolol in hypertensive Jamaicans." I was slightly surprised to find a reply to it from Dr G A C Grell (29 July, p 358) appearing some 10 years later in your columns. However, I must accept all constructive criticism, however delayed, as valid.

Briefly, back in 1968 (in the early days of propranolol) Humphreys and I did a doubleblind trial in which we were unable to find any hypotensive effect in Jamaicans. We were as bewildered then as to the mechanism of 
action of propranolol in hypertension as I myself remain to this day. However, we theorised rather optimistically that the drug's central tranquillising effect might have something to do with it. That effect, we thought, might have rather more value in an overstressed London businessman than in a peaceful Jamaican farmer.

Ten years later Dr Grell comes up with no less than nine Jamaican patients in some of whom there is a good fall in blood pressure while in a few there is actually a rise in supine systolic pressure. Perhaps he is simply rather better at getting his patients to take their tablets than we were. But I would point out that our study of propranolol in hypertension was actually double-blind, unlike previous studies which, like the present one of Dr Grell, were totally uncontrolled. The effect on a patient's blood pressure of an enthusiastic and (I imagine) sympathetic doctor like Dr Grell should not be underestimated. This effect is particularly marked when at the same time the patient's anxiety decreases as he gradually gets used to having his blood pressure taken.

Those who assess new antihypertensives over the next 10 years should bear these two phenomena in mind. In short, all trials of antihypertensive drugs should be doubleblind.

D G Delvin

Chislehurst Common, Kent ' Humphreys, G S, and Delvin, D G, British Medical
fournal, 1968, 2, 601.

\section{Carcinoma of the male breast and oestrogen metabolism}

SIR,-Tamoxifen has been generally available for just over five years, the original clinical studies having been carried out at this hospital about seven years ago. Given the rarity of male breast carcinoma it is not surprising that Drs D B Jefferys and J Efthimiou and Dr R Abele and others (24 June, p 1697) and Drs D A L Morgan and Anne Hong (15 July, p 206) could report on only one or two cases treated with the drug.

I have treated eight patients with metastatic male breast carcinoma with tamoxifen and have a further three patients taking the drug as adjuvant therapy following simple mastectomy and radiotherapy. However, I feel that no meaningful conclusions can be drawn until between 20 and 30 patients have been treated.

Historically, a similar situation appertained to stilboestrol, reports on the usefulness or uselessness of the drug being based on the treatment of less than 10 patients. A series from this hospital showed an overall response of $38 \%$ to stilboestrol therapy in 55 patients with metastatic male breast carcinoma. ${ }^{1}$ However, no response was obtained in patients with bone metastases and from the experience of Treves ${ }^{2}$ and this hospital ${ }^{3}$ it would seem that ablative operations may still be the treatment of choice in that situation.

The response of $38 \%$ to stilboestrol in advanced male breast carcinoma is very similar to the female response rate and it will be surprising if an approximately similar rate is not achieved for tamoxifen, as a $30 \%$ rate for advanced female breast carcinoma is commonly achieved.

In a collaborative study, just being completed, 11 patients with male breast carcinoma have had serum levels of 17- $\beta$-oestradiol, follicle-stimulating hormone, luteinising hormone, and testosterone estimeted. These levels have been compared with those from 40 normal controls (10 for each decade from 30 to 80 years). The results of this study will be published in due course.

Christie Hospital and Holt Radium

G G RIBEIRo Institute,
Manchester

1 Ribeiro, G G, British fournal of Cancer, 1976, 33, 465. Treves, N, Cancer, 1959, 12, 820 64, 381 .

\section{Behcet's disease}

SIR,-With reference to your leading article on this disease (22 July, p 234), it may be worth mentioning two other forms of treatment which have been reported as being of benefit.

The first is the use of fibrinolytic agentsphenformin and ethyloestrenol ${ }^{1-3}$ and streptokinase. ${ }^{4}$ The rationale for this is that vasculitis and deep venous thrombosis are prominent features and that fibrinolysis has been shown to be impaired in some patients with the condition..$^{5-7}$

The second line of therapy has recently been reported from Japan, where the disease is rather more common. ${ }^{8}$ In this report the authors record overall benefits with the use of colchicine in 131 cases and remark that the drug is now "widely used" for Behçet's disease in Japan. The theoretical reason for this is colchicine's inhibition of polymorph chemotaxis, which is reportedly elevated in the disease. ${ }^{9}$

While both of these therapeutic regimens are as yet unproved by controlled trial and analysis, they seem to be valuable methods to consider for patients with this condition, especially since they are relatively free from serious side effects.

R GRAHAM-BROWN

Department of Dermatology,

Royal Free Hospital,

1 Cunliffe, W J, and Menon, I S, Lancet, 1969, 1, 1239. Kirk, J, and Handley, D A, Australian fournal of Dermatology, 1972, 13, 5 .

2,486, British Medical Fournal, 1973, Chajek,

1973, 1,782.

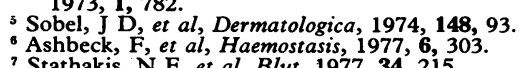

' Stathakis, N E, et al, Blut, 1977, 34, 215. 8 Mitzushima, Y, et al, Lancet, 1977, $2,1037$.
Sobel, J D, et al, Journal of Clinical Pathology, 1977,
30, 250.

\section{Prevalence of multiple sclerosis in West Yorkshire}

SIR,-Last year we contacted the general practitioners in the Calderdale area of West Yorkshire who have computer-produced agesex registers and asked them for the number of patients in their practices and the number of their patients with accepted multiple sclerosis (MS). Like Drs David I Shepherd and Allan W Downie (29 July, $p$ 314) in north-east Scotland, we found a higher prevalence rate of MS than we had expected-120 cases in a surveyed population of 157400 or a rate of 76 cases per 100000 population. We found some practices within the area to have unexpectedly high prevalence rates, one as high as 217 per 100000 . In one practice centred on Hebden Bridge we were able to examine all patients firmly diagnosed by consultant physicians as having MS. This mixed urbanrural practice of 16500 patients is the only general practice covering the area and had 21 patients with a diagnosis of MS. The female:male ratio was $3: 1$ and mean age at presentation 29 years. Two patients had been diagnosed before they moved into the area. Excluding four patients who do not meet all of Schumacher's diagnostic criteria, ${ }^{1}$ principally because of recent onset, a prevalence rate of 103 per 100000 is still higher than expected.

We share Drs Shepherd and Downie's view that general practices possessing agesex-morbidity registers can be productive epidemiologically. In addition we feel that information obtained from such registers is most useful when it comes from practices which cover a circumscribed geographical area exclusively, as comparison with larger studies is often possible.

We thank the Calderdale practitioners for their help in giving figures and Mrs C M Ingham for secretarial help.

M MCCOUBRIE

Hebden Bridge, w Yorks

D SHUTTLEWORTH

University College Hospital,

on $\mathrm{WCl}$

Schumacher, G A, et al, Annals of the New York Academy of Sciences, 1965, 122, 522 .

\section{“A-Z Pregnancy and Babycare"}

SIR,-A number of statements have appeared recently in the press to the effect that the Royal Society of Medicine does not support this publication wholeheartedly and, by inference, that it lacks confidence in Health Care Periodicals Ltd and in its managing director, Mr J Scott-Clark.

It should therefore be put on record: firstly, that the decision that the society should engage more actively in health education and in publishing, both for members of the medical profession and for the lay public, was taken by the council more than two years ago and has repeatedly been reaffirmed by them and by the Scientific and Executive Committee; secondly, that the honorary editors of the society who, under the bylaws, are given such authority, approved the publication of the $A-Z$ Pregnancy and Babycare in February 1977; thirdly, that its editor-in-chief, Dr Hugh Jolly, was invited to accept that position by the honorary editors and did so in order to assist the society; and, fourthly, that the society stands fully behind Health Care Periodicals Ltd in the publication and distribution of the book.

It should also be known that for some years the society's Open Section has accommodated members from many walks of life and has arranged meetings for the discussion of subjects of common concern to the medical profession and the general public; that some of its principal lectures are addressed to the laity; and that it has organised lunchtime lectures by its fellows on medical subjects for lay audiences as a contribution to health care. These activities continue and they were forerunners of the enlarged publication programme of which the $A-Z$ Pregnancy and Babycare is but one part. 